\title{
О КУЛЬТУРНОЙ ПРИНАДЛЕЖНОСТИ НОВЫХ ПАМЯТНИКОВ ЭПОХИ БРОНЗЫ СТЕПНОГО И ЛЕСОСТЕПНОГО ЗАУРАЛЬЯ
}

Павел Федорович Кузнецов

Самарский государственный социально-педагогический университет, Самара, Россия E-mail: pavelf.kpf.kuznetsov@gmail.com

\begin{abstract}
Аннотация. Статья посвящена анализу новых памятников лесостепного и степного Зауралья. Это два круглоплановых поселения - Улак-1 и Селек, а также два неукрепленных поселения - Коноплянка 2 и Каменный Брод. В результате анализа керамических коллекций поселения Улак-1 выясняется, что наиболее ранний слой относится к абашевской культуре. Оба круглоплановых поселения находятся за пределами ареала укрепленных поселений синташтинской культуры. Последние расположены по отношению к друг другу не случайным образом. К абашевским материалам относится и большая часть керамики поселения Каменный Брод. Напротив, к синташтинской культуре относится наиболее ранняя коллекция неукрепленного поселения Коноплянка 2, которое расположено вблизи укрепленного поселения Коноплянка. Открытие новых памятников в Зауралье предполагает выделение особого зауральского варианта абашевской культуры, которая предшествует синташтинской.
\end{abstract}

Ключевые слова: Зауралье, Волго-Уралье, бронзовый век, круглоплановые поселения, неукрепленный поселения, абашевская культура, синташтинская культура

Цитирование. Кузнецов П.Ф., 2021. О культурной принадлежности новых памятников эпохи бронзы степного и лесостепного Зауралья // Уфимский археологический вестник. Т.21, №2. С.264-273. DOI: https://doi.org/10.31833/uav/2021.21.2.006

UDC 902

Submitted: 29.09 .2021

LBC 63.4

Accepted: 18.10 .2021

\section{ON THE CULTURAL ATTRIBUTION OF NEWLY DISCOVERED BRONZE AGE SITES IN STEPPE AND FOREST-STEPPE TRANS-URALS}

\author{
Pavel F. Kuznetsov \\ Samara State University of Social Sciences and Education, Samara, Russia \\ E-mail: pavelf.kpf.kuznetsov@gmail.com
}

\begin{abstract}
This paper presents the analysis of several newly discovered archaeological sites located in the forest-steppe and steppe Trans-Urals. These are the circular settlements of Ulak-1 and Selek and two unfortified settlements - Konoplyanka 2 and Kammeny Brod. Most archaeologists attribute the first two settlements to the Sintashta culture, although a careful analysis of pottery assemblages from the sites allow us to attribute them to the Abashevo culture. Unlike Sintashta settlements, characterized by a ditch and a rampart, which were used to protect the main fortifications during military conflicts, the settlements of Ulak-1 and Selek have trenches that functioned as water control structures. These structures did not play any protective role against military attacks. Moreover, both circular settlements are situated outside the scientifically established area of the Sintashta culture distribution. The earliest ceramics assemblages from Konoplyanka 2 settlement clearly belong to the Sintashta culture. However, pottery fragments discovered at the settlement of Kamenny Brod demonstrate the features of both Abashevo and Sintashta cultures. Thus, archaeological evidence suggests, that there is a unique Trans-Urals variant of the Abashevo culture, which preceded the Sintashta culture in this region, dating back to the end of the Middle Bronze Age. The newly discovered data also supports the fact that not all Sintashta settlements had fortifications. Further research is needed to specify the chronological limits of the cultures under discussion and to explore new archaeological sites related to the topic.

Keywords: Trans-Urals, Volga-Urals, Bronze Age, circular settlements, unfortified settlements, Abashevo culture, Sintashta culture

Citation. Kuznetsov P., 2021. On the cultural attribution of newly discovered Bronze Age sites in steppe and foreststeppe Trans-Urals. Ufimskij arkheologicheskiy vestnik [The Ufa Archaeological Herald]. Vol.21, no. 2, pp. $264-273$. (In Russ.). DOI: https://doi.org/10.31833/uav/2021.21.2.006

\section{Введение}

Самарская археологическая школа своим происхождением обязана Башкирской, так как в 1969 году из Уфы в Самару, в связи с открытием нового университета, переехали Г.И. Матвеева и И.Б.Васильев. С тех времен взаимосвязь археологов двух городов не прекращалась. Проводились совмест-

ные экспедиции, участниками которых в разные годы были наши уфимские коллеги - В.С.Горбунов, В.А. Иванов, Ю.А. Морозов, М.Ф. Обыденнов, Н.Г. Рутто. У меня, как специалиста по эпохе бронзы, всегда была прочная взаимосвязь с Г.Б.Здановичем и М.Ф.Обыденновым. Их вклад в науку неоспорим. При этом, корифеи уральской
\end{abstract}


археологии передали лучшие научные традиции следующему поколению исследователей. Для меня особенно интересны публикации по бронзовому веку более молодых, но очень опытных уфимских коллег: И.И. Бахшиева, М.С. Чаплыгина, И.А. Шутелевой, Н.Б.Щербакова. Тем более, что эти публикации связаны с изучением блока колесничных и непосредственно предшествующих ему культур. Исследования круглоплановых поселений на территории Башкирского Зауралья, проводимых в последние годы, представляется чрезвычайно ценным вкладом в изучение историко-культурных процессов всего Урало-Поволжского региона.

\section{Круглоплановые}

\section{поселения Башкирского Зауралья}

В Башкирском Зауралье сейчас активно исследуется новый тип памятников. Это поселения Улак-1 и Селек, которые открыты сравнительно недавно [Савельев, Яминов, 2004. С. 204-215; Котов, Савельев, 2021. С. 17-29]. Особенность круглоплановой топографии памятников объективно способствовала их отнесению к синташтинской культуре [Савельев, Яминов, 2004. С.214; Бахшиев, 2014. С. 11-24; Бахшиев, Насретдинов, 2016. С. 64-87]. Но, есть и некоторые специфические особенности этих памятников. Прежде всего, обращает на себя внимание то, что они расположены сравнительно близко друг к другу (рис. 1). Расстояние между ними составляет порядка 8,3 км. Из 22 укрепленных поселений синташтинской культуры («Страны городов», по образному выражению Г.Б.Здановича) есть 13 поселений, из всех близкорасположенных памятников, которые имеют расстояния от 32 до 41 км (рис. 1; 2). Расстояние в 8 км встречено всего один раз - между памятниками Каменный Амбар и Журумбай. Здесь же, в 10 км друг от друга расположены укрепленные поселения Журумбай и Коноплянка. Но это своеобразный эпицентр синташтинской культуры. Максимальное освоение центральной части географического ареала любого социо-культурного явления отражает его объективную эволюцию.

Укрепленные поселения синташтинской культуры расположены по отношению к друг другу тремя основными цепочками, вытянутыми по линии северо-восток - юго-запад. В этих цепочках известны 5, 6 памятников (рис. 2). С юга и с севера по отношению к этим трем цепочкам расположены по одной паре укрепленных синташтинских поселений [Зданович Г., Батанина, 2007. Рис. 1]. Полагаю, что такое их взаиморасположение не случайно. Но это тема специального исследования. Здесь же необходимо отметить то обстоятельство, что ареал синташтинской культуры в пределах Зауральского пенеплена топографически вписывается в окружность диаметром около 200 км. Памятники Улак-1 и Селек находятся за её пределами.

Геофизические и дистанционные исследования поселения Улак-1, дополненные в 2015 году раскопками, позволили установить его топографические и архитектурные особенности [Бахшиев, Насретдинов, 2016]. В этой связи чрезвычайно важными мне представляются два наблюдения. Первое - малая глубина кольцевого рва. Он углублен в материк на 7-40 см [Бахшиев, Насретдинов, 2016. С.87. Рис. 12]. В отличие от него, глубина рвов собственно синташтинских поселений находится в интервале от 0,8 до 3,5 м [Семьян, 2014. С. 109]. Вполне справедливо предположение И.И.Бахшиева о том, что ров и вал - это скорее гидротехнические сооружения, чем оборонительные. Второе - в процессе раскопок под валом была зафиксирована искусственная яма овальной формы, углубленная в материк. На этом основании авторы делают вполне закономерный вывод о том, что первоначально данное поселение функционировало без ровика и без вала.

Коллекция керамики,

опубликованная

И.И. Бахшиевым и Р.Р. Насретдиновым, достаточно уверенно датируется эпохой бронзы. Авторы выделяют группу керамики, которую относят к синташтинской культуре (рис. 3). Но при детальном рассмотрении такая культурная атрибуция вызывает определенные сомнения. Из 11 фрагментов керамики четыре венчика имеют явное утолщение профиля к его срезу [Бахшиев, Насретдинов, 2016. Рис. 2, 1, 2, 5, 6, 8]. Это есть один из основных признаков горшковидных сосудов абашевской культуры Южного Урала [Кузьмина, 1992. Табл. 5, 1]. Семь фрагментов орнаментированы канелюрами-желобками, украшающими верхнюю часть сосуда [Бахшиев, Насретдинов, 2016. Рис. 2, 1-5, 7, 8]. Этот элемент орнамента также характерен для южноуральской абашевской керамики [Кузьмина, 1991. С. 31]. Два венчика имеют валики-утолщения [Бахшиев, Насретдинов, 2016. Рис. 2, 6, 10], что также является абашевским признаком горшковидных сосудов [Кузьмина, 1992. С.33]. Один фрагмент стенки сосуда украшен лесенкой, имеющей наклонную штриховку [Бахшиев, Насретдинов, 2016. Рис. 2, 11] и такой орнамент характерен для абашевских сосудов [Кузьмина, 1992. С.30]. И, наконец, судя по фото сосуда с утолщением-валиком, глиняное тесто имеет характерную для абашевской культуры пористую структуру [Бахшиев, Насретдинов, 2016. Рис. 2, 10]. Один фрагмент стенки, судя по его орнаментации, может быть отнесен к покровской культуре [Бахшиев, Насретдинов, 2016. Рис. 2, 9]. Таким образом, ранний этап поселения Улак-1 соответствует абашевской культуре. Ни одного фрагмента керамики, имеющего характерные синташтинские признаки, здесь неизвестно. Последующие этапы функционирования поселения относятся ко времени покровской и срубной культур. Вероятно, к этому времени относятся и гидротехнические сооружения в виде ровика и вала. Сооружения, имеющие круглоплановое взаиморасположение, вписаны в кольцевую структуру вала. Соответственно, и они относятся ко времени покровской (позднего этапа), либо срубной культур.

Итак, ранний этап поселения Улак-1 относится ко времени абашевской культуры. В 8 км к юговостоку от него в 2003 г. обнаружено круглопла- 


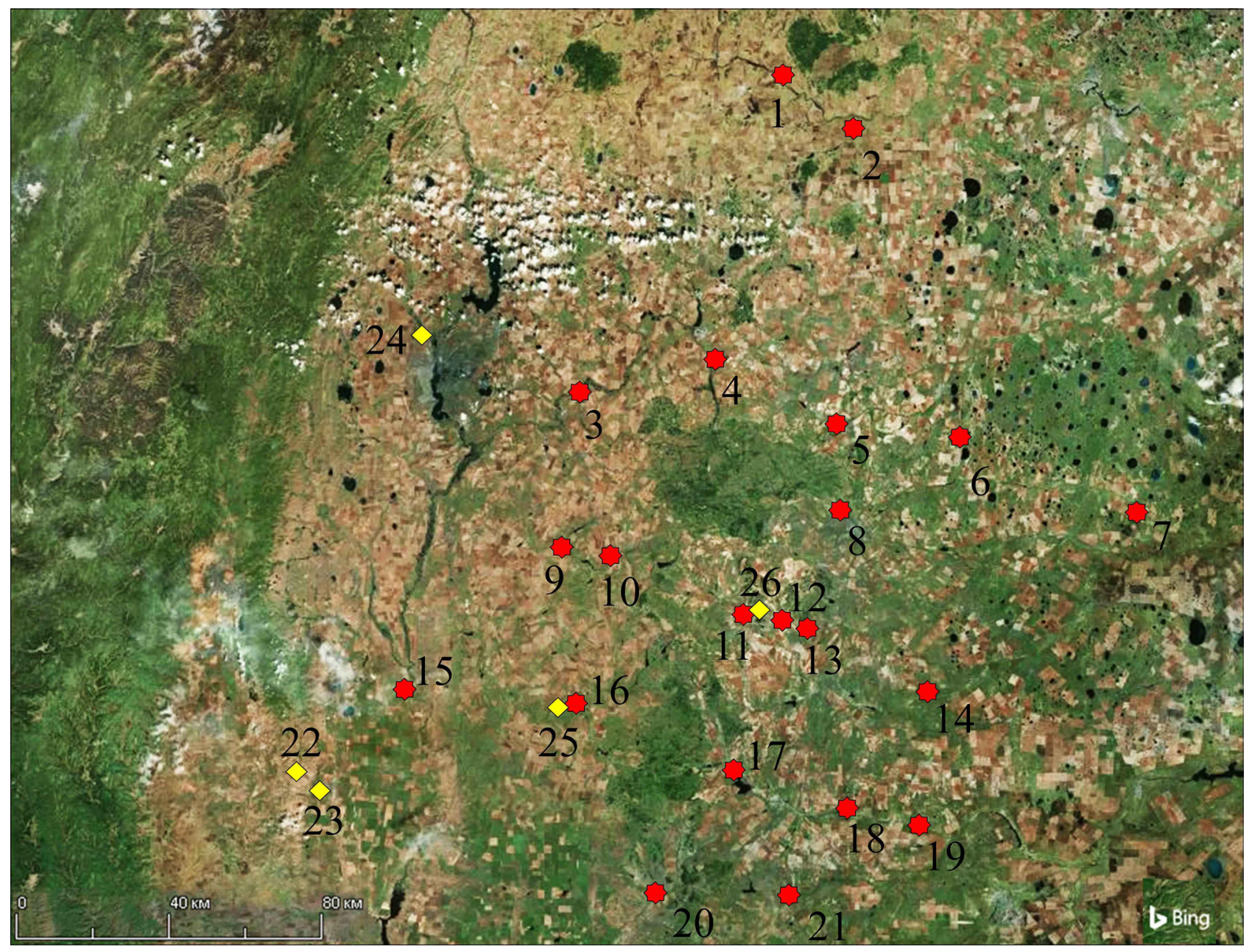

Рис. 1. Карта памятников абашевской и синташтинской культур на территории степного и лесостепного Зауралья.

1-21 - укрепленные поселения синташтинской культуры (по: [Зданович Г., Батанина, 2007]: 1 - Степное; 2 - Черноречье; 3 - Бахта; 4 - Париж; 5 - Устье; 6 - Чекатай; 7 - Исиней; 8 - Родники; 9 - Куйсак; 10 - Сарым-Саклы; 11 - Коноплянка; 12 - Журумбай; 13 - Каменный Амбар; 14 - Камысты; 15 - Кизильское; 16 - Аркаим; 17 - Синташта; 18 - Синташта II; 19 - Андреевское; 20 - Аландское; 21 - Берсуат; 22, 23 - круглоплановые поселения Улак-1 (22) и Селек (23) (по: [Бахшиев, Насретдинов, 2016; Котов, Савельев, 2021]); 24 - Мало-Кизыльское поселение абашевской культуры (по: [Сальников, 1967]); 25 - неукрепленное поселение Каменный Брод (по: [Малютина, Зданович Г., 2012]; 26 - неукрепленное поселение Коноплянка 2 (по: [Корякова и др., 2020])

Fig. 1. Map of the archaeological sites of the Abashevo and Sintashta cultures in the steppe and forest-steppe Trans-Urals.

1-21 - fortified settlements of the Sintashta culture (after: [Zdanovich, Batanina, 2007]: 1 - Stepnoe; 2 - Chernorech'e; 3 - Bahta; 4 - Paris; 5 - Ust'e; 6 - Chekatai; 7 - Isinei; 8 - Rodniki; 9 - Kujsak; 10 - Sarym-Sakly; 11 - Konoplyanka; 12 - Zhurumbai; 13 - Kamenny Ambar; 14 - Kamysty; 15 - Kizil'skoe; 16 - Arkaim; 17 - Sintashta; 18 - Sintashta II; 19 - Andreevskoe; 20 - Alandskoe; 21 - Bersuat; 22, 23 - circular settlements Ulak-1 (22) and Selek (23) (after: [Bakhshiev, Nasretdinov, 2016; Kotov, Savelev, 2021]); 24 - Maly-Kizyl settlement of the Abashevo culture (after: [Salnikov, 1967]); 25 - unfortified settlement of Kamenny Brod, (after: [Malyutina, Zdanovich, 2012]; 26 - unfortified settlement of Konoplyanka 2, (after: [Koryakova et al., 2020])

новое поселение Селек [Котов, Савельев, 2021]. В разведочном шурфе здесь было обнаружено 8 фрагментов керамики, которые авторы относят к синташтинской, алакульской и саргаринской культурам [Котов, Савельев, 2021. С.23]. Два фрагмента - венчик и стенку они определили как синташтинские [Котов, Савельев, 2021. Рис. 6, 2, 3]. Оба фрагмента имеют желобки. Но, они настолько фрагментарны, что в равной степени могут быть отнесены как к синташтинской, так и к абашевской культурам.

Оба круглоплановых паселения находятся в западной части Зауралья - на территории, примыкающей к восточному склону Южного Урала, на правых притоках р. Урал. В аналогичных условиях, в 120 км к северу находится широко известное Мало-Кизыльское поселение абашевской культу- ры. То есть, данная территория органично входит в ареал зауральского варианта абашевской культуры, которую К.В.Сальников именовал Магнитогорским [Сальников, 1967. С. 124-127].

\section{Неукрепленные поселения Зауралья}

Насколько глубоко носители абашевской культуры могли проникнуть за р.Урал? А.Д.Пряхин считал, что они распространились до р. Тобол, именуя синташтинские памятники синкретическими абашевско-алакульскими [Пряхин, 1977. С. 119]. В этой связи весьма актуален вопрос выявления собственно абашевских памятников на территории Урало-Тобольского междуречья. Как абашевская была определена постройка на линии 2 поселения Коноплянка 2 [Корякова и др., 2020. С. 69]. Это неукрепленное поселение находится в пятистах метрах от укрепленного поселения Коноплянка, 


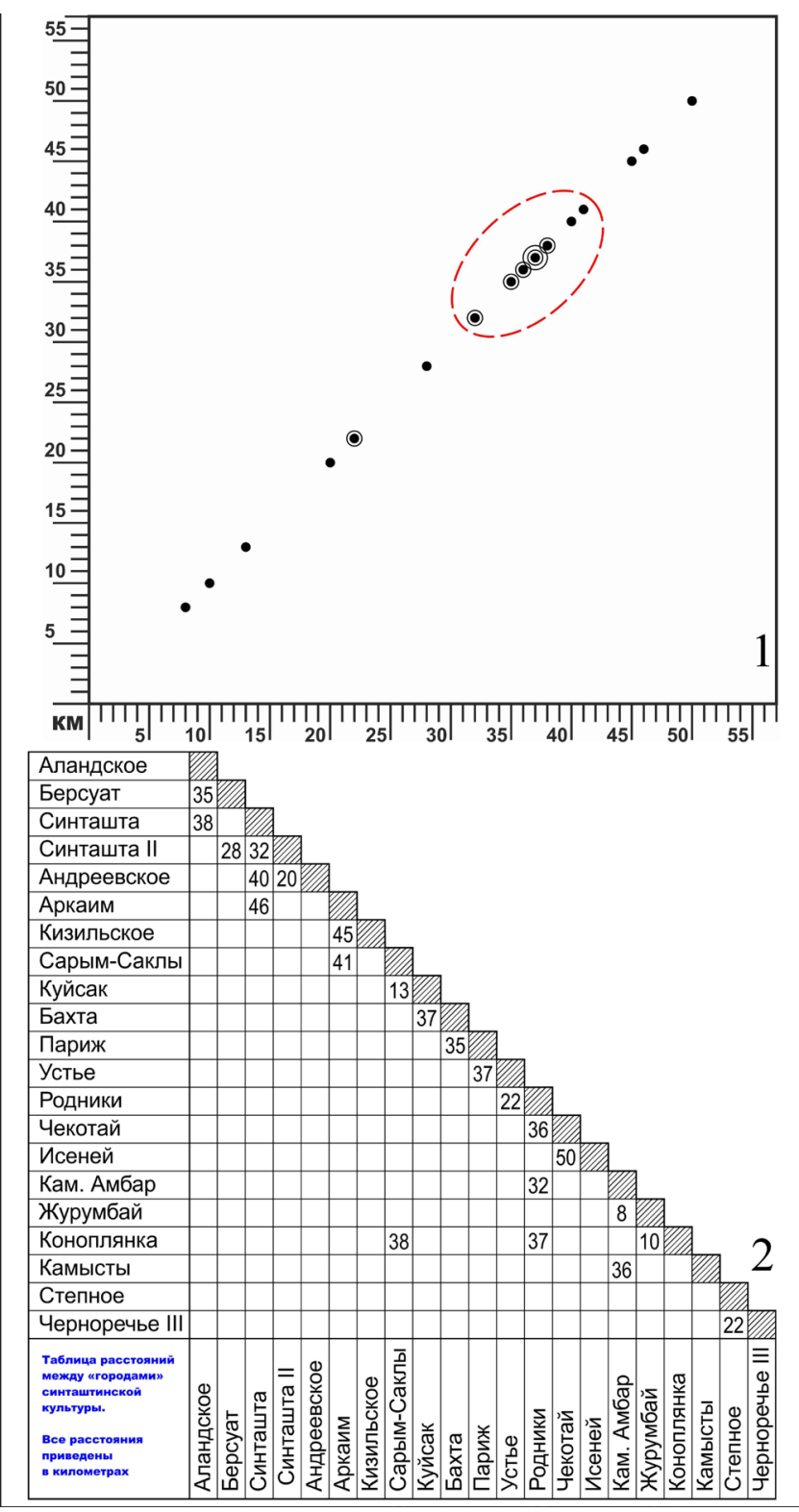

Рис.2. Расстояния всех близкорасположенных укрепленных поселений синташтинской культуры. 1 - график расстояний; 2 - таблица расстояний соседних укрепленных поселений (в км)

Fig. 2. Distances to all nearby fortified settlements of the Sintashta culture. 1 - distance graph; 2 - table of distances of neighboring fortified settlements (in $\mathrm{km}$ )

на противоположном (левом) берегу р. Акмулла [Корякова и др., 2020. Рис. 1]. Коллекция опубликованной керамики поселения, интерпретируемой как абашевская, невелика - всего восемь фрагментов [Корякова и др., 2020. Рис. 7]. Тем не менее, она имеет ряд выразительных признаков (рис. 4).

По мнению О.В.Кузьминой, данную коллекцию целесообразно сравнить с представительной абашевской коллекцией Мало-Кизыльского поселения Зауралья. ' Тем более, что эта керамика хорошо проанализирована и опубликована [Сальников, 1967. С. 73, 80, 81; Епимахов, Епимахова, 2006. C. 60,61$]$. При детальном сравнении можно увидеть вполне очевидные различия. Так, абашевские сосуды Мало-Кизыльского поселения имеют почти прямой, утолщенный вверху венчик и тонкие стенки, а у керамики поселения Коноплянка 2 есть профилированный венчик, утончающийся кверху, а стенки толще венчика по линии его среза. Разительны и отличия в орнаментации посуды. Два венчика поселения Коноплянка 2 украшены шнуровым орнаментом [Корякова и др., 2020. Рис. 7, 5, 6]. На керамике Мало-Кизыльского поселения такой способ нанесения орнамента отсутствует [Епимахов, Епимахова, 2006. С. 56]. Впрочем, во всем ареале абашевской культуры Волго-Уралья шнуровой способ орнаментации керамики мне не известен. Есть существенные различия и в орнаментальных композициях. Керамика Мало-Кизыльского поселения имеет снизу и сверху двойной зигзаг, а керамика Коноплянки 2 - одинарный. Мало-Кизыльская керамика имеет внутри пояска из парных зигзагов два мотива из многорядного зигзага, с оставлением между ними пустого пространства. Керамика Коноплянки 2 имеет только один мотив из крупного зигзага.

Вывод вполне очевиден - керамика неукрепленного поселения Коноплянка 2 не является абашевской. Эту коллекцию возможно интерпретировать как синташтинскую. Четыре венчика имеют горшковидную плавную профилировку [Корякова и др., 2020. Рис. 7, 1, 3, 5, 6]. Такие плавнопрофилированные синташтинские сосуды В.В.Ткачевым и А.И.Хаванским выделены в отдельные подтипы III.1.1 и III.2.1 [Ткачев, Хаванский, 2006. С.29, 156-163). В отличие от сосудов с ребристым профилем, эта керамика украшена намного скромнее. Преобладают горизонтальный и вертикальный зигзаг и прямые линии, имитирующие желобки. Орнамент, как и на поселении Коноплянка 2, выполнен зубчатым штампом, веревочкой и прочерчиванием. Есть и прямые аналогии орнаментальным композициям на синташтинском и потаповском сосудах [Ткачев, Хаванский, 2006. Рис. 56, 4; Васильев и др., 1994. Рис. 19, 2; 25, 1].

В связи с тем, что типология синташтинской керамики была разработана по погребальным комплексам, для поиска аналогий коноплянской керамике необходимо обратиться к синташтинским поселенческим памятникам. В связи с фрагментарностью материала, большее внимание уделялось орнаментальным композициям и способу их нанесения.

1.Горшковидный сосуд пос. Коноплянка 2, украшенный горизонтальными рядами елочки, выполненной крупнозубчатым штампом [Корякова и др., 2020. Рис. 7, 1]. Аналогичный орнамент есть на пос. Синташта [Генинг и др., 1992. Рис. 26, 7]. Есть он и на пос. Устье [Древнее Устье..., 2013. Рис. 2.16, 6].

\footnotetext{
${ }^{1}$ Выражаю искреннюю признательность О.В. Кузьминой за деятельное обсуждение основных положений и выводов данной работы. Также я глубоко благодарен М.К. Петровской за уточнение терминологии из англоязычного корпуса источников по географии, архитектуре и военному делу.
} 

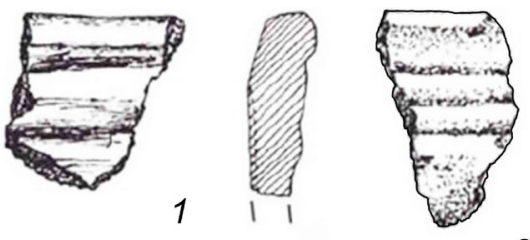

2
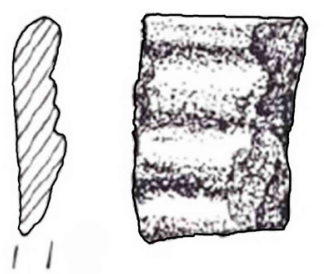

3
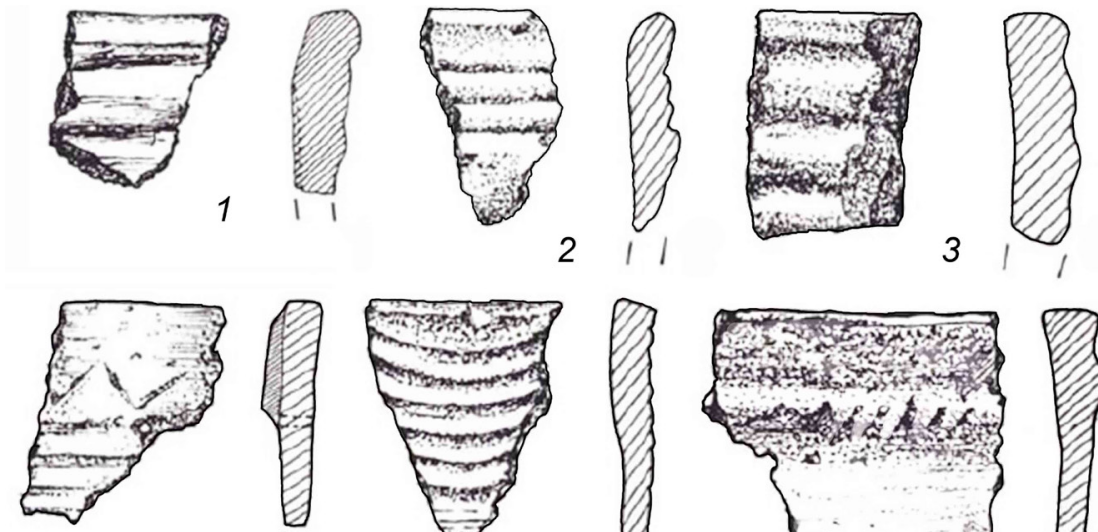

4
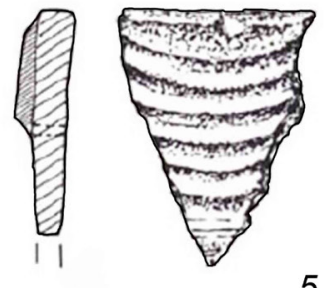

5
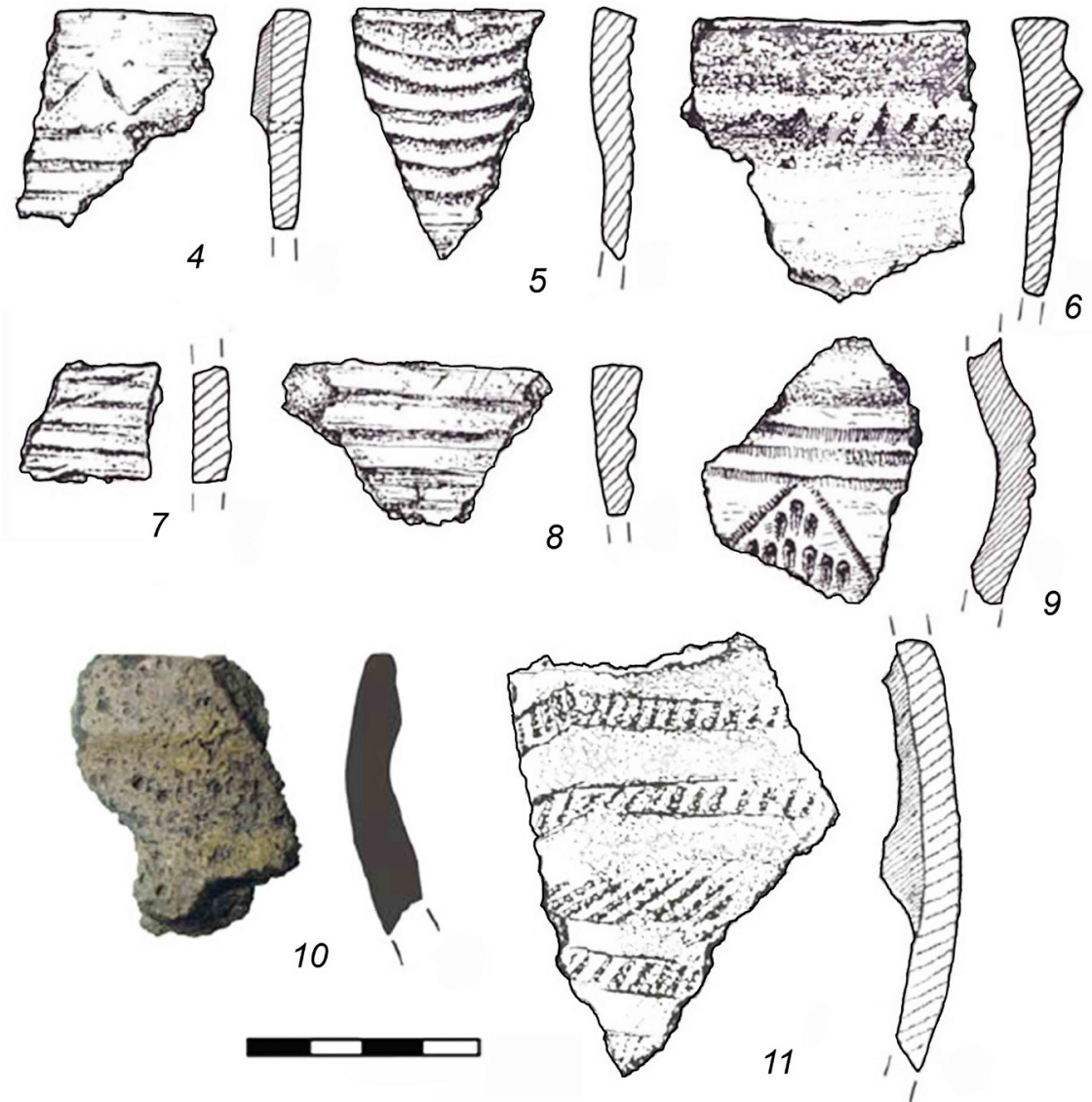

9

Рис. 3. Керамика поселения Улак-1 (по [Бахшиев, Насретдинов, 2016. Рис. 2])

Fig. 3. Pottery assemblages from Ulak-1 settlement, (after: [Bakhshiev, Nasretdinov, 2016. Fig. 2])

2.Баночный сосуд, украшенный горизонтальными рядами ямочных отпечатков [Корякова и др., 2020. Рис. 7, 2]. Похожий орнамент есть на пос. Аркаим [Зданович Г. и др., 2020. Рис. 2.2.5, 7 , $14 ; 3.2 .10,5]$.

3. Слабопрофилированный горшковидный сосуд, украшенный рядами горизонтальной елочки и прямыми линиями, имитирующими желобки [Корякова и др., 2020. Рис. 7, 3]. Такая орнаментация есть на фрагментах пос. Аркаим и Синташта [Зданович Г. и др., 2020. Рис. 2.3.10, 6; Генинг и др., 1992. Рис. 25, 4].

4.Баночный сосуд, украшенный горизонтальными рядами елочки и наклонными рядами отпечатков зубчатого штампа [Корякова и др., 2020. Рис. 7, 4]. Сходный орнамент есть на баночном сосуде пос. Синташта [Генинг и др., 1992. Рис.26, 15].

5. Горшковидный сосуд, украшенный отпечатками горизонтальных рядов и елочки, выполненный отпечатками шнура [Корякова и др., 2020. Рис. 7,5$]$. Аналогичный орнамент есть на фрагменте из пос. Синташта и Устье [Генинг и др., 1992. Рис. 26, 5; Древнее Устье..., 2013. Рис. 2.37, 9].
6. Горшковидный сосуд, украшенный горизонтальной елочкой из отпечатков шнура [Корякова и др., 2020. Рис. 7, 6]. Похожие композиции, выполненные шнуром, есть на пос. Устье [Древнее Устье..., 2013. Рис. 2.39, 4, 11].

7. Венчик гошковидного сосуда, украшенный горизонтальными рядами желобков [Корякова и др., 2020. Рис. 7, 7]. Такой же орнамент есть на керамике пос.Аркаим и Устье [ЗдановичГ. и др., 2020. Рис. 2.6.8, 4; 2.12.10, 1; Древнее Устье..., 2013. Рис. $2.37,6]$.

8. Венчик сосуда, украшенный желобками, рядами горизонтальной елочки и короткими наклонными отпечатками. Способ нанесения не ясен [Корякова и др. 2020. Рис. 7, 8]. Аналогичная композиция есть на фрагментах пос. Синташта [Генинг и др., 1992. Рис. 23, 7$].$

Таким образом, анализ ранней керамики поселения Коноплянка 2 позволяет отнести её к синташтинской культуре. На этой керамике нет ярко выраженных геометрических композиций. Да и сама коллекция невелика. Но, комплексный анализ не вызывает сомнений в её культурной принадлежности. Важно сравнить эту коллекцию с керамикой 

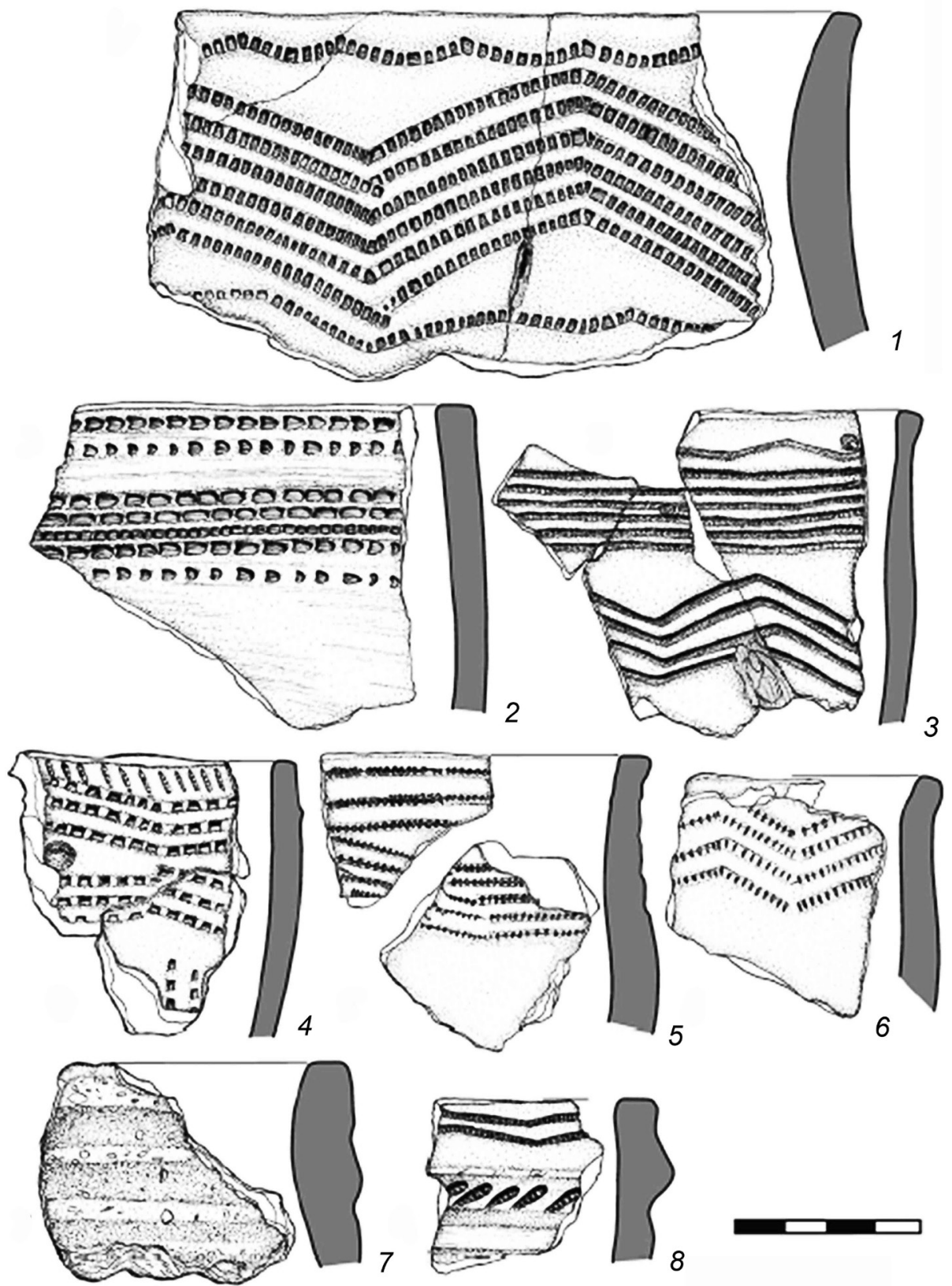

3

Рис. 4. Керамика поселения Коноплянка 2 (по: [Корякова и др., 2020. Рис. 7])

Fig. 4. Pottery assemblages from Konoplyanka 2 settlement, (after: [Koryakova et al., 2020. Fig. 7])

укрепленного поселения Коноплянка. Г.Б.Зданович и И.М. Батанина пишут о том, что сборы с поверхности синташтинской керамики были [Зданович Г., Батанина, 2007. С. 112]. Также необходимо учитывать, что на топографическом плане у авторов вплотную к пос. Коноплянка 2 показано неукрепленное поселение Коноплянка-I [Зданович Г., Батанина, 2007. Рис.57]. Возможно, что это есть один и тот же памятник.

Наличие синташтинского культурного слоя на неукрепленном поселении Коноплянка 2 допускает существование открытых поселков за пределами фортификационных сооружений [ЗдановичГ., Батанина, 2007. С. 191; Малютина, ЗдановичГ., 2012. С. 60; Зданович Д., Зданович Г., 2014. С. 57]. Но данных для этого сейчас немного.

В 2012 году Т.С.Малютина и Г.Б.Зданович публикуют результаты исследований поселения Каменный Брод, который авторы интерпретиру- ют как поселение-спутник укрепленного центра Аркаим, находящегося в 1 км к северу от него [Малютина, Зданович Г., 2012. С. 52]. Но, при детальном рассмотрении, аркаимская/синташтинская принадлежность всей коллекции керамики поселения Каменный Брод вызывает сомнения (рис.5). Однозначно, к синташтинской не может быть отнесен неорнаментированный баночный сосуд с округлым дном [Малютина, Зданович Г., 2012. Рис. 4, 10]. На памятнике есть выразительный набор кремневых изделий. И данный сосуд вполне может быть отнесен ко времени до начала позднего бронзового века [Потемкина, Дегтярева, 2008. Рис. 2, 2, 4; 5, 4]. В коллекции поселения имеются пять фрагментов венчиков плавнопрофилированных горшковидных сосудов [Малютина, Зданович Г., 2012. Рис. 4. 1, 2, 4, 5, 7]. Все они обладают выраженным абашевским признаком - утолщением венчика по отношению к стенкам. 

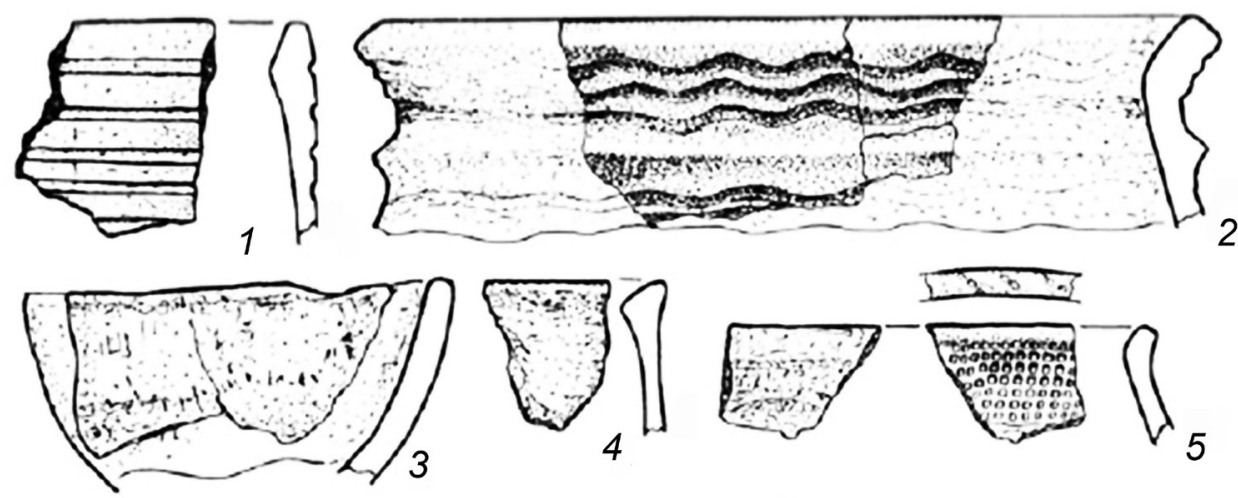

\section{,}
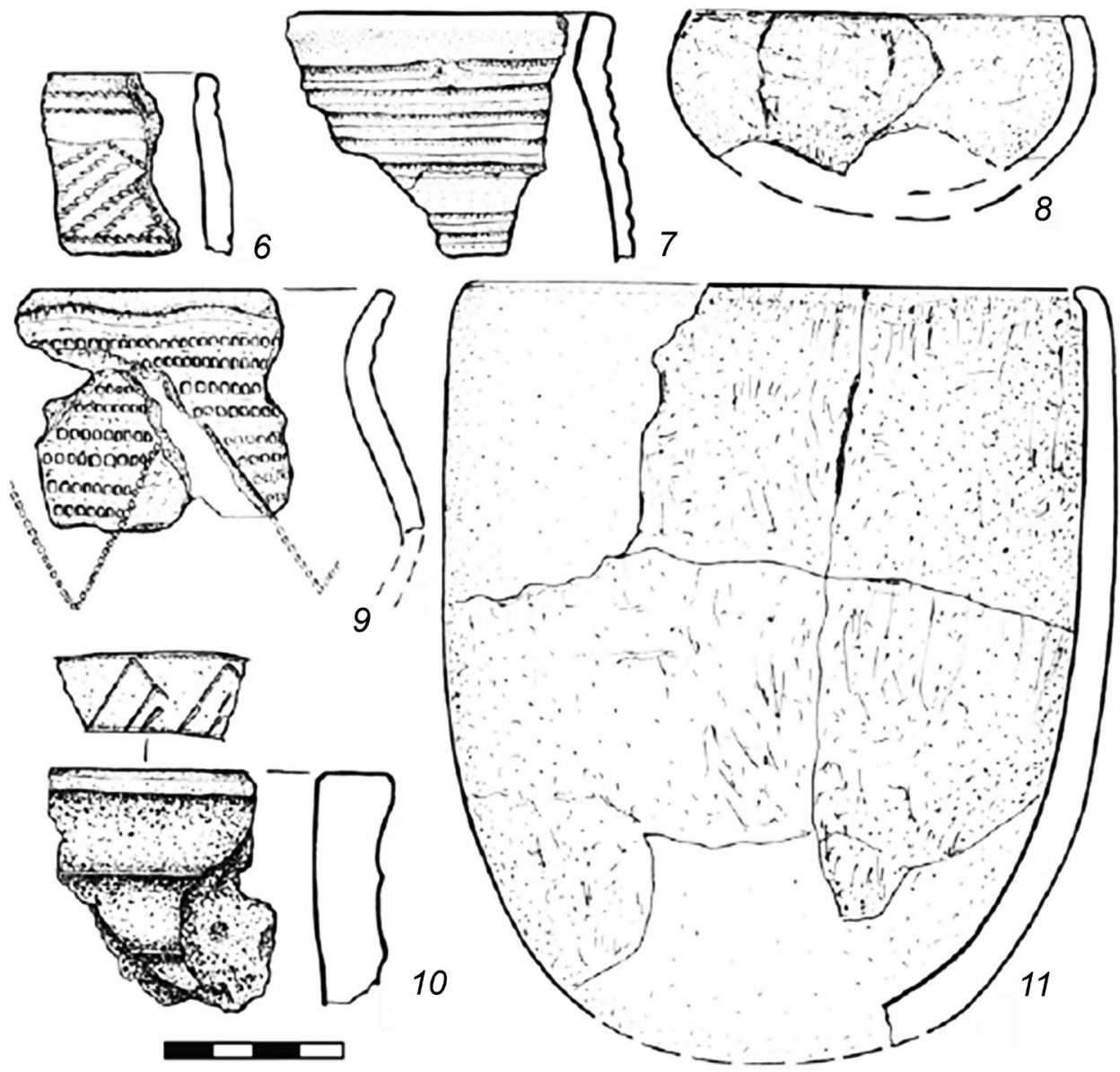

Рис. 5. Керамика поселения Каменный Брод (по: [Малютина, Зданович, 2012. Рис. 4])

Fig. 5. Pottery assemblages from Kamenny Brod settlement, after: [Malyutina, Zdanovich, 2012. Fig. 4])

Их орнаментация горизонтальными желобками, волной и рядами вдавлений также вполне абашевская. Фрагмент сосуда с S-видным профилем в сочетании с орнаментом имеет прямые аналогии на Мало-Кизыльском поселении [Малютина, ЗдановичГ., 2012. Рис. 4, 9; Сальников, 1967. Рис. 12, 19; Епимахов, Епимахова, 2006. Рис. 1, 1, 17, 23]. Фрагмент венчика с орнаментом по срезу слишком мал, чтобы определить его культурную атрибуцию [Малютина, Зданович Г., 2012. Рис. 4, 10]. Два чашевидных сосуда в равной степени могут быть определены и как абашевские, и как синташтинские [Малютина, Зданович Г., 2012. Рис. 4, 3, $8]$. И лишь один фрагмент венчика, украшенный шнуровым орнаментом, возможно интерпретировать как синташтинский [Малютина, ЗдановичГ., 2012. Рис. 4, 6].

\section{Выводы}

В результате проведенного исследования мы получили подтверждение наличия поселенческих памятников абашевской культуры в Зауралье. К ним, помимо Мало-Кизыльского поселения, возможно добавить поселения Селек и Каменный Брод. Основной ареал Зауральского варианта абашевской культуры - территория от восточного склона Уральских гор и до правого берега р. Урал. Наличие абашевского комплекса на поселении Каменный Брод свидетельствует о проникновении его носителей на территорию Урало-Тобольского междуречья. Это не первый памятник абашевской культуры, находящийся за пределами её основной территории. Так, абашевский комплекс поселения Серный Ключ находится в горно-лесной зоне Среднего Урала [Борзунов и др., 2020. С. 128]. Это 
своеобразные абашевские экспедиции за пределы основного ареала культуры [Древности..., 2018. C. 32-34, 153].

Рассмотренные материалы являются новым подтверждением формирования синташтинской культуры на основе абашевской на территории Южного Урала. Порой, при самом общем взгляде на коллекции, абашевская и синташтинская керамика воспринимаются как нечто общее. Эта взаимосвязь отражает преемственность. Ареалы двух культур в пределах степного Приуралья практически совпадают. И данные стратиграфии, и обнаружение новых памятников на этой территории не оставляют сомнений в их различной хронологической позиции. В этой связи, важно, что в культурно-хронологической схеме В.С. Бочкарева абашевский металл был отнесен к концу эпохи средней бронзы, а синташтинский и раннепокровский - к
I периоду эпохи поздней бронзы [Бочкарев, 2017. C. 163]. Радиоуглеродные датировки абашевской и синташтинской культур частично накладываются. Но это вполне объяснимо тем обстоятельством, что доверительный интервал достоверных дат имеет диапазон от 160 до 60 лет, тогда как реальное время культур с конца эпохи средней бронзы обретает высокую динамику и охватывает интервал в 200-300 лет.

Открытие неукрепленных поселений синташтинской культуры объективно подтверждает гипотезу И.М.Батаниной, Г.Б.Здановича, Д.Г.Здановича и Т.С. Малютиной о различных типах памятников. Но, построению разнообразных культурологических моделей должен предшествовать этап археологического исследования окрестностей всех укрепленных поселений.

\section{СПИСОК ЛИТЕРАТУРЫ}

Бахшиев И.И. Поселения эпохи поздней бронзы Башкирского Зауралья // Процесс культурогенеза начальной поры позднего бронзового века Волго-Уральского региона (вопросы хронологии, периодизации, историографии). Материалы междунар. науч. конф. 12-14 мая 2014 года. Самара: ПГСГА, 2014. С. 11-24.

БахииевИ.И., Насретдинов Р.Р. Некоторые итоги исследований 2015-2016гг. на поселении Улак-1 в Башкирском Зауралье // Историко-культурные процессы на Южном Урале в эпоху поздней бронзы: современные проблемы изучения и сохранения культурного наследия. Материалы Всерос. науч.-практ. конф., посвящ. 70-летию со дня рождения Н.Г. Рутто. Уфа: Диалог, 2016. С. 64 87.

Борзунов В.А., Стефанов В.И., БельтиковаГ.В., Кузьминых С.В. Серный ключ - памятник абашевской «экспедиции» в горно-лесную зону Среднего Урала // Российская археология. № 1. 2020. С. 117-131. DOI:10.31857/ S086960630003392-0

Бочкарев В.С. Этапы развития металлопроизводства эпохи поздней бронзы на юге Восточной Европы // Stratum plus: Archaeology and Cultural Anthropology. № 2. 2017. C. 159-204.

ВасильевИ.Б., КузнеиовП.Ф., СеменоваА.П. Потаповский курганный могильник индоиранских племен на Волге. Самара: Самарский университет, 1994. 208 c.

Генинг В.Ф., Зданович Г.Б., ГенингВ.В. Синташта. Археологические памятники арийских племен Урало-Казахстанских степей. Часть 1. Челябинск: ЧелГУ. 1992. 408 с.

Древнее Устье: укрепленное поселение бронзового века в Южном Зауралье / Отв. ред. Н.Б. Виноградов. Челябинск: Абрис, 2013. 482 с.

Древности Башкирского Урала: коллективная монография / Отв. ред. и сост. Н.С. Савельев. Уфа: Информреклама, 2018. 216 с.

Eпимахов A.B., Епимахова М.Г. Абашевские памятники Южного Зауралья // Урало-Поволжская лесостепь в эпоху бронзового века: сборник статей, посвящ. 60-летию Владимира Степановича Горбунова / Отв. ред. Г.Т. Обыденнова. Уфа: БГПУ, 2006. C. 53-64.

ЗдановичД.Г., ЗдановичГ.Б. Аркаим: археологический источник и его модель (проблемы и перспективы) // Процесс культурогенеза начальной поры позднего бронзового века Волго-Уральского региона (вопросы хронологии, периодизации, историографии). Материалы междунар. науч. конф. 12-14 мая 2014 года. Самара: ПГСГА, 2014. C. 55-64.

Зданович Г.Б. Батанина И.М. Аркаим - Страна городов: Пространство и образы (Аркаим: горизонты исследований). Челябинск: Крокус, 2007. $260 \mathrm{c}$.

ЗдановичГ.Б., Малютина Т.А., ЗдановичД.Г. Аркаим. Археология укреплённых поселений. Книга 1: Жилища и жилое пространство. Челябинск: ЧелГУ, 2020. 450 с.

Котов В.Г., СавельевН.С. Укрепленное поселение Селек эпохи бронзы в Башкирском Зауралье (итоги исследований 2003 года) // Археология Евразийских степей. №2. 2021. С. 17-27. DOI: 10.24411/2587-6112-2021-10010

КоряковаЛ.Н., КраузеР., ПантелееваС.Е., СтолярчикЭ., БулаковаЕ.А., СолдаткинН.В., Рассадников А.Ю., Молчанова В.В., Анкушев М.Н., МолчановИ.В., ЯкимовА.С., ФедороваН.В., Носкевич B.B. Поселение Коноплянка 2 в Южном Зауралье: новые аспекты исследования // Уральский исторический вестник. №4(69). 2020. С.61-73. DOI:10.30759/1728-9718-2020-4(69)-61-73

КузьминаО.В. Абашевская культура в лесостепном Волго-Уралье: Учебное пособие к спецкурсу. Самара: Самарский педагогический институт, 1992. $128 \mathrm{c}$.

Малютина Т.А., Зданович Г.Б. Поселение «Каменный Брод» - спутник укрепленного центра Аркаим: стратиграфические горизонты и ритмы 
повторов жизненных циклов в «Стране городов» // Археологические памятники Оренбуржья. Вып. 10 / Отв. ред. Н.Л. Моргунова. Оренбург: ОГПУ, 2012. C. 50-62.

Потемкина Т.М., ДегтяреваА.Д. Металл ямной культуры Притоболья // Вестник археологии, антропологии и этнографии. № 8. 2008. С. 18-39.

Пряхин А.Д. Погребальные абашевские памятники. Воронеж: Воронежский университет, 1977. $168 \mathrm{c}$.

Савельев Н.С., Яминов А.Ф. Улак-1 - новое укрепленное поселение эпохи бронзы в Башкирском Зауралье // Народы Южного Урала и их соседи в древности и средневековье. Материалы междунар. науч. конф., посвящ. 70-летию круп- ного археолога-историка и общественного деятеля Н.А. Мажитова. Уфа: БашГУ, 2004. С. 204-218.

Сальников К.В. Очерки древней истории Южного Урала. М.: Наука, 1967. 408 с.

Семьян И.А. Военный фактор в культурогенезе синташтинских памятников по материалам укрепленных поселений // Процесс культурогенеза начальной поры позднего бронзового века Волго-Уральского региона (вопросы хронологии, периодизации, историографии). Материалы междунар. науч. конф. 12-14 мая 2014 года. Самара: ПГСГА, 2014. С. 107-113.

Ткачев В.В., ХаванскийА.И. Керамика синташтинской культуры. Самара; Орск: ОГТИ, 2006. $180 \mathrm{c}$.

\section{REFERENCES}

Bahshiev, I.I. "Settlements of the Late Bronze Age in the Bashkir Trans-Urals region", Process kul'turogeneza nachal'noj pory pozdnego bronzovogo veka Volgo-Ural'skogo regiona (voprosy hronologii, periodizacii, istoriografii). Materialy mezhdunar. nauch. konf. 12-14 maya 2014 goda ("Process of the cultural genesis at the early stage of the Late Bronze age in the Volga-Ural region (problems of chronology, periodisation and historiography). Proceedings of the international scientific conference 12-14 May 2014"). Samara, 2014, pp. 11-24. (In Russ.)

Bahshiev, I.I., Nasretdinov, R.R. "Some results of research conducted in 2015-2016 at the Ulak-1 settlement in the Bashkir Trans-Urals region", Istoriko-kul'turnye processy na Yuzhnom Urale v epohu pozdnej bronzy: sovremennye problemy izucheniya $i$ sohraneniya kul'turnogo naslediya. Materialy Vseros. nauch.-prakt. konf., posvyashch. 70-letiyu so dnya rozhdeniya N.G. Rutto ("Historical and cultural processes in the South Urals during the Late Bronze Age: actual problems of study and preservation of cultural heritage. Proceedings of the All-Russian scientific and practical conference to the $70^{\text {th }}$ anniversary of the birth of N.G. Rutto"). Ufa, 2016, pp. 64-87. (In Russ.)

Borzunov, V.A., Stefanov, V.I., \& Beltikova, G.V., Kuzminyh, S.V. 2020, "Serny klyuch - the site of the Abashevo "expedition" to the mountain forest zone of the Middle Urals", Russian Archaeology], no. 1, pp. 117-131. doi:10.31857/S086960630003392-0. (In Russ.)

Bochkarev, V.S. 2017, "Stages in the development of metal production in the Late Bronze Age in the south part of Eastern Europe", Stratum plus, no. 2, pp. 159-204. (In Russ.)

Vasilev, I.B., Kuznetsov, P.F., \& Semenova, A.P. 1994, "Potapovka barrow necropolis of the Indo-Iranian tribes on the Volga river". Samarskij universitet, Samara, 207 p. (In Russ.)

Gening, V.F., Zdanovich, G.B., \& Gening, V.V. 1992, "The Sintashta culture. Archaeological sites of the Aryan tribes in the Ural-Kazakhstan steppes. Part 1". ChelGU, Chelyabinsk, 408 p. (In Russ.)

Alaeva, I.P., Bachura, O.P., \& Vinogradov, N.B., Grigorev, S.A., Gutkov,A.I., Degtyareva,A.D.,
Deryagin, V.V., Dunan, R.K., Kosintsev, P.A., Kuzminykh, S.V., $\quad$ Kungurova, N.Y., $\quad$ Levit, A.I., Mori, M., Mosin, V.S., Muzhich,B., Medarich, I., Pitman, D., Usachuk,A.N., Henks, B.K., Checushkov,I.V., Epimahov,A.V. 2013, "Drevnee Ust'e: a fortified settlement of the Bronze Age in the Southern Trans-Urals region". Abris, Chelyabinsk, 482 p. (In Russ.)

Savelev, N.S., Kotov, V.G., Ovsyannikov, V.V., Rumyantsev, M.M., Ruslanov, E.V., Akhmetova, E.A. 2018, "Antiquities of the Bashkir Urals region: a collective monograph”. Informreklama, Ufa, 216p. (In Russ.)

Epimahov, A.V., Epimahova, M.G. "Archaeological sites of the Abashevo culture in the Southern Trans-Urals", Uralo-Povolzhskaya lesostep'v epokhu bronzovogo veka: sbornik statej, posvyashch. 60-letiyu Vladimira Stepanovicha Gorbunova ("The UralVolga forest steppe in the Bronze Age: a collection of papers to the $60^{\text {th }}$ anniversary of the birth of Vladimir Stepanovich Gorbunov"). Ufa, 2006, pp. 53-64. (In Russ.)

Zdanovich, D.G., Zdanovich, G.B. "Arkaim: archaeological sourse and its model (problems and perspectives)", Process kul'turogeneza nachal'noj pory pozdnego bronzovogo veka Volgo-Ural'skogo regiona (voprosy hronologii, periodizacii, istoriografii). Materialy mezhdunar. nauch. konf. 12-14 maya 2014 goda ("Process of the cultural genesis at the early stage of the Late Bronze age in the Volga-Ural region (problems of chronology, periodisation and historiography). Proceedings of the international scientific conference 12-14 May 2014"). Samara, 2014, pp. 55-64. (In Russ.)

Zdanovich, G.B. Batanina, I.M. 2007, “Arkaim Country of Towns: space and symbols (Arkaim: perspectives of research)". Krokus, Chelyabinsk, $260 \mathrm{p}$. (In Russ.)

Zdanovich,G.B., Malyutina,T.A., \& Zdanovich,D.G. 2020, "Arkaim. Archeology of fortified settlements. Book 1: Dwellings and living spaces". ChelGU, Chelyabinsk, 450p. (In Russ.)

Kotov, V.G., Savelev, N.S. 2021, "Selek - a fortified settlement of the Bronze age in the Bash- 
kir Trans-Urals (study results of 2003)", Archaeology of the Eurasian steppes, no.2, pp.17-27. doi:10.24411/2587-6112-2021-10010. (In Russ.)

Koryakova, L.N., Krauze, R., \& Panteleeva, S.E., Stolyarchik, E., Bulakova, E.A., Soldatkin, N.V., Rassadnikov, A.Y., Molchanova, V.V., Ankushev, M.N., Molchanov,I.V., $\quad$ Yakimov, A.S., $\quad$ Fedorova, N.V., Noskevich, V.V. 2020, "Konoplyanka2 settlement in the Southern Trans-Urals region: new aspects of research", Ural Historical Journal, no. 4, vol.69, pp. 61-73. doi:10.30759/1728-9718-2020-4(69)-6173. (In Russ.)

Kuzmina, O.V. 1992, "The Abashevo culture in the forest-steppe Volga-Ural region: A student's handbook to the academic minor". Samarskij pedagogicheskij institute, Samara, 128 p. (In Russ.)

Malyutina, T.A., Zdanovich, G.B. 2012, "Kamennyj Brod settlement - a satellite of the fortified settlement Arkaim: stratigraphic horizons and repetition patterns of the life cycles in the "Country of Towns", Arheologicheskie pamyatniki Orenburzh'ya, iss. 10, pp. 50-62. (In Russ.)

Potemkina, T.M., Degtyareva,A.D. 2008, "Metal of the Yamnaya culture of the region near the Tobol river", Journal of the archaeology, anthropology and ethnography, no. 8, pp. 18-39.

Pryakhin,A.D. 1977, "The Abashevo burial sites". Voronezhskiy universitet, Voronezh, $168 \mathrm{p}$. (In Russ.)
Savelev, N.S., Yaminov, A.F. "Ulak-1 - a new fortified settlement of the Bronze Age in the Bashkir Trans-Urals region", Narody Yuzhnogo Urala i ih sosedi v drevnosti i srednevekov'e. Materialy mezhdunar. nauch. konf., posvyashch. 70-letiyu krupnogo arheologa-istorika $i$ obshchestvennogo deyatelya N.A. Mazhitova ("Peoples of the Southern Urals and their neighbours in the Antient times and Middle Ages. Proceedings of the international scientific conference devoted to the $70^{\text {th }}$ anniversary of the birth of a famous archaeologist and historian and a public figure N.A. Mazhitov"). Ufa, 2004, pp. 204-218. (In Russ.)

Salnikov, K.V. 1967, "Essays on the Ancient History of the Southern Ural". Nauka, Moscow, 408p. (In Russ.)

Semyan, I.A. "Military factor in the cultural genesis of the Sintashta sites based on the assemblages from fortified settlements", Process kul'turogeneza nachal'noj pory pozdnego bronzovogo veka VolgoUral skogo regiona (voprosy hronologii, periodizacii, istoriografii). Materialy mezhdunar. nauch. konf. 1214 maya 2014 goda ("Process of the cultural genesis at the early stage of the Late Bronze age in the VolgaUral region (problems of chronology, periodisation and historiography). Proceedings of the international scientific conference 12-14 May 2014"). Samara, 2014. pp. 107-113. (In Russ.)

Tkachev, V.V., Khavanskiy,A.I. 2006, "Pottery of the Sintashta culture". OGTI, Samara, Orsk, 180 p. (In Russ.)

\section{Сведения об авторе}

Павел Федорович Кузнецов, кандидат исторических наук, доцент, заведующий музеем археологии Поволжья Самарского государственного социально-педагогического университета, Российская Федерация, г. Самара. E-mail: pavelf.kpf.kuznetsov@gmail.com, ORCID: 0000-0002-4898-5350

\section{Information About the Author}

Pavel F. Kuznetsov, Ph.D., associate professor, head of the Museum of Archaeology of the Volga region of the Samara State University of Social Sciences and Education, Russian Federation, Samara. E-mail: pavelf. kpf.kuznetsov@gmail.com, ORCID: 0000-0002-4898-5350 